\title{
Isolation, proliferation, and induction of Bama mini-pig spermatogonial stem cells in vitro
}

\author{
H.M. Zhao' ${ }^{1}$, H. Yang' ${ }^{1}$, F.H. Luo ${ }^{2}$, M.X. Li ${ }^{1}$, S. Zhang1, X.G. Yang ${ }^{1}$, \\ Y.Q. $\mathrm{Lu}^{1}$, S.S. Lu${ }^{1}$, Y.J. Wu ${ }^{2}$ and K.H. $\mathrm{Lu}^{1}$ \\ ${ }^{1}$ State Key Laboratory for Conservation and Utilization of Subtropical \\ Agro-bioresources, \\ Guangxi High Education Laboratory for Animal Reproduction and Biotechnology, \\ Guangxi University, Nanning, China \\ ${ }^{2}$ Key Laboratory of National Education Ministry for Mammalian \\ Reproductive Biology and Biotechnology, Inner Mongolia University, \\ Hohhot, China \\ Corresponding authors: K.H. Lu / Y.J. Wu \\ E-mail:khlu@gxu.edu.cn / wuyj1211@163.com \\ Genet. Mol. Res. 15 (3): gmr.15038602 \\ Received March 7, 2016 \\ Accepted April 15, 2016 \\ Published August 12, 2016 \\ DOI http://dx.doi.org/10.4238/gmr.15038602 \\ Copyright $(2016$ The Authors. This is an open-access article distributed under the terms of \\ the Creative Commons Attribution ShareAlike (CC BY-SA) 4.0 License.
}

ABSTRACT. Spermatogonial stem cells (SSCs), the unique seed cells
of testes, can undergo meiosis and form spermatozoa, thus transmitting
genetic information to offspring. Research concerning these cells
explores the mechanism underlying spermatogenesis, making possible
the induction of their differentiation into spermatozoa in vitro. SSCs
have therefore attracted much interest among scientists. Although
the proliferation of such cells in vitro has been demonstrated, we are
unaware of any long-term laboratory culture of porcine SSCs. The
objective of this study was to isolate, characterize, culture, and induce
the differentiation of Bama mini-pig SSCs. SSCs were isolated using
differential plating and cultured for over 100 days on an STO feeder 
cell layer without serum. Cell clusters appeared after three passages and continuously formed during subsequent cultivation. Staining showed that these clusters were positive for UCHL1 and CDH1, could be bound by Dolichos biflorus agglutinin, and that some cells expressed OCT4. Ultrastructure observations revealed SSCs in testis tissue to be round in shape, while those cultured in vitro were flat and bound together. Our attempts at inducing differentiation showed that SSCs cultured in vitro could undergo meiosis. In this study, we describe an effective culture system for Bama mini-pig SSCs capable of producing enough cells to establish a platform for further SSC research, such as genetic manipulation or exploration of the mechanism underlying spermatogenesis.

Key words: Bama mini-pig; Spermatogonial stem cell; Stem cell cultivation; Stem cell differentiation

\section{INTRODUCTION}

Spermatogonial stem cells (SSCs), the foundation of spermatogenesis in testes, are located within a microenvironmental niche in the basement membrane of the seminiferous tubule. These cells are one of the vehicles through which genetic information is transmitted from one generation to another, and have therefore gained much attention because of their potential value in the production of transgenic animals (Takehashi et al., 2010). Proliferation of SSCs can provide enough cells for genetic manipulation to be carried out. The creation of transgenic SSCs and injection of the resulting spermatozoa into oocytes could be used to produce genetically modified embryos, providing an efficient method for transgenic animal production based on normal fertilization.

The isolation, cultivation, and induced differentiation of SSCs will enable infertile men to father their own offspring. Recent research has shown that SSCs isolated from neonatal mice have the ability to generate pluripotent cells (Guan et al., 2006). Moreover, SSCs can be transformed to exhibit embryonic stem cell (ESC)-like qualities and pluripotency (Lim et al., 2013). Zhou et al. (2016) reported that murine germ cells derived from ESCs can undergo meiosis and be used to produce transgenic mice. In addition, the differentiation of bovine germline stem cells has been induced in vitro, revealed by expression of meiosis markers such as stimulated by retinoic acid 8 and synaptonemal complex protein 3 (Li et al., 2016). Such research demonstrates the feasibility of inducing SSC differentiation and spermatid formation, providing hope for azoospermic men who wish to father children.

In recent years, a number of SSC markers have been discovered, providing a convenient method for the identification of these cells in vitro. Cadherin-1 (CDH1) expression has been detected in type A spermatogonia in mouse testis tissue and used to identify mouse SSCs (Tokuda et al., 2007). Octamer-binding transcription factor 4 (OCT4), promyelocytic leukemia zinc finger protein, VASA, and glial cell line-derived neurotrophic factor (GDNF) family receptor alpha-1 (GFra1) are expressed in undifferentiated SSCs in mouse testes, and are considered molecular markers of these cells (Pesce et al., 1998; Tanaka et al., 2000; Buaas et al., 2004; von Schönfeldt et al., 2004). Oatley et al. (2011) reported that inhibitor of DNA binding 4 is only expressed by type A single spermatogonia, and thus should be a dependable

Genetics and Molecular Research 15 (3): gmr.15038602 
SSC indicator. In mammals, several molecular markers have also been identified, including Dolichos biflorus agglutinin (DBA), which specifically binds to undifferentiated male germ cells in piglet testes (Goel et al., 2007). In addition, ubiquitin carboxyl-terminal hydrolase1 (UCHL1), expressed in undifferentiated pig testis germ cells, has been used to identify SSCs in bovine and porcine testes (Goel et al., 2007; Fujihara et al., 2011). THY1 cell surface antigen is known to be expressed by SSCs in many domestic animals, including pigs and goats (Wu et al., 2013; Zheng et al., 2013). The discovery of these markers makes possible the identification of SSCs cultured in vitro.

Until recently, the growth of SSCs in the laboratory has been highly challenging owing to the absence of an appropriate culture system, but in the past 10 years, great progress has been made thanks to the discovery of factors supporting the proliferation of these cells. Among these is GDNF, a member of the transforming growth factor- $\beta$ superfamily. GDNF was originally identified because of its role in supporting midbrain dopaminergic neurons, and is normally secreted by Sertoli cells. Previous research has shown that GDNF overexpression blocks the differentiation process, leading to the accumulation of undifferentiated male germ cells in mice (Meng et al., 2000). Moreover, SSCs are capable of proliferating in medium supplemented with basic fibroblast growth factor (bFGF) and GDNF (Kanatsu-Shinohara et al., 2005). GFral also promotes SSC growth in vitro (Kubota et al., 2004). The characterization of these growth factors allows the culture of SSCs in the laboratory. The establishment of efficient culture systems is of great value to the study of these cells, permitting them to be produced in sufficient quantities for basic research or genetic modification. The first successful long-term culture of mouse germline stem cells employed mitomycin C-inactivated embryonic fibroblasts (Kanatsu-Shinohara et al., 2003). Recently, it has been demonstrated that SSCs are able to proliferate in a novel culture system from which both a feeder layer and serum are omitted (Kanatsu-Shinohara et al., 2011). Buffalo SSCs have been cultured in vitro (Kala et al., 2012). while in 2013, the in vitro proliferation of porcine SSCs for 60 days at $31^{\circ} \mathrm{C}$ was reported (Lee et al., 2013). Mouse SSCs can be multiplied in medium supplemented with Knockout Serum Replacement (Aoshima et al., 2013). These cells have also been maintained for 5 months in laminin-coated dishes without serum (Kanatsu-Shinohara et al., 2014). Shortterm cultures of human SSCs have been established (Zheng et al., 2014) while their bovine equivalents can be grown in cultures lacking both serum and a feeder layer (Li et al., 2016). However, to the best of our knowledge, porcine SSCs have not been successfully proliferated long-term in vitro.

The Bama mini-pig is a domestic animal in China reared for both economic reasons and scientific research (Hu et al., 2015); therefore, we used it as a model in the current work to investigate SSCs.

\section{MATERIAL AND METHODS}

\section{Animals}

A 1-month-old Bama mini-pig was obtained from the Animal Experiment Center of our university. The pig lived in an enclosed barn kept at $20^{\circ} \mathrm{C}$ and was fed daily. The procedures involving animals carried out in this study complied with the guidelines of the Animal Care and Use Committee of the Germplasm Resource Center of the Chinese Experimental Mini-pig and the Institutional Animal Care and Use Committee of Guangxi University.

Genetics and Molecular Research 15 (3): gmr.15038602 
H.M. Zhao et al.

\section{Isolation of SSCs}

SSCs were isolated from the testis of the abovementioned Bama mini-pig. The collected testes were placed on ice and transported to the laboratory within $20 \mathrm{~min}$. Isolation of SSCs was performed as follows: testes were sterilized in $75 \%$ alcohol for $10 \mathrm{~min}$, washed three times in Dulbecco's phosphate-buffered saline (DPBS; catalogue No. 21600010; Gibco, Carlsbad, CA, USA), decapsulated, rinsed three times with DPBS, and minced with sterilized scissors into small pieces, before $2 \mathrm{~g}$ testis tissue was harvested for digestion. The tissue was suspended in Dulbecco's modified Eagle's medium (DMEM)/F12 containing $1 \mathrm{mg} / \mathrm{mL}$ collagenase (Sigma, St. Louis, MO, USA) and $5 \mu \mathrm{g} / \mathrm{mL}$ DNase I, incubated at $37^{\circ} \mathrm{C}$ for $40 \mathrm{~min}$ in a shaking waterbath operated at 90 cycles/min, and washed three times in DMEM/F12 to remove most of the interstitial cells. The seminiferous tubules were harvested and incubated in DMEM/F12 containing $1 \mathrm{mg} / \mathrm{mL}$ collagenase, $5 \mu \mathrm{g} / \mathrm{mL}$ DNase I, $1.5 \mathrm{mg} / \mathrm{mL}$ hyaluronidase, and $0.25 \%$ trypsin-ethylenediaminetetraacetic acid for $30 \mathrm{~min}$ under the conditions described above. Digestion was terminated by adding DMEM/ F12 containing 10\% fetal bovine serum (FBS; HyClone, Logan, UT, USA), before harvesting and suspending the dispersed cells in DMEM/F12, and successively filtering them through 70and 40- $\mu \mathrm{m}$ cell strainers (BD Biosciences Discovery Labware, Woburn, MA, USA). After a 60-h incubation at $32.5^{\circ} \mathrm{C}$ on gelatin-coated dishes containing DMEM/F12 with $10 \% \mathrm{FBS}$, unattached cells were collected. Differential plating was then carried out for further purification as follows: the harvested cells were incubated for $4 \mathrm{~h}$ at $32.5^{\circ} \mathrm{C}$ on collagen-coated dishes containing DMEM/F12 with $10 \%$ FBS, then unattached cells were collected and re-plated on laminin-coated dishes, before a 2-h incubation in the same medium. Finally, the attached cells were harvested.

\section{Immunohistochemistry of testicular tissue}

Immunohistochemical staining was performed to identify SSCs in tissue sections. The primary antibody used was rabbit anti-human protein gene product 9.5 (UCHL1; 1:200 dilution; AbD Serotec, Kidlington, UK), whereas the corresponding secondary antibody was Alexa Fluor488-labeled donkey anti-rabbit immunoglobulin g (1:500 dilution; Invitrogen Molecular Probes, Eugene, OR, USA). Sections were also stained with rhodamine-labeled DBA (1:100 dilution; Vector Laboratories, Inc., Burlingame, CA, USA). Antibodies and DBA were diluted using 3\% bovine serum albumin (BSA; Sigma) in PBS.

Immunohistochemical staining was carried out as follows: sections were dewaxed, rehydrated, placed in a microwavable container with $500 \mathrm{~mL} 10 \mathrm{mM}$ sodium citrate, $\mathrm{pH}$ 6.0, heated for $10 \mathrm{~min}$ at $90^{\circ} \mathrm{C}$ in a microwave for antigen retrieval, and incubated with $0.5 \%$ Triton X-100 for 15 min. After being blocked in 10\% normal goat serum in DMEM/F12 for $30 \mathrm{~min}$, sections were incubated with $200 \mu \mathrm{L}$ primary antibody at $37^{\circ} \mathrm{C}$ for $3 \mathrm{~h}$, then $200 \mu \mathrm{L}$ secondary antibody at room temperature for $1 \mathrm{~h}$. Following a final incubation with $200 \mu \mathrm{L}$ $10 \mathrm{mg} / \mathrm{mL}$ Hoechst 33342 for $3 \mathrm{~min}$ to visualize nuclei, the sections were washed in PBS and mounted with VECTASHIELD mounting medium (Vector Laboratories, Inc.). For double staining, rhodamine-labeled DBA (1:100 dilution) was mixed with the secondary antibody solution. Primary antibody was replaced by $3 \%$ BSA in PBS for the negative control.

\section{In vitro culture of isolated SSCs}

Harvested cells were seeded on a mitomycin-treated STO feeder layer and incubated

Genetics and Molecular Research 15 (3): gmr.15038602 
on culture dishes containing a serum-free patented medium (patent No. CN201210549380.5). The cells were cultured in a $5 \% \mathrm{CO}_{2}$ atmosphere at $37^{\circ} \mathrm{C}$, with the medium being changed daily. After 4-5 days, cells were collected by gentle pipetting, and passaged to a new STO feeder layer.

\section{Immunocytochemical staining of SSCs}

Germ cell clusters were characterized by double staining with rhodamine-labeled DBA (1:100 dilution) and primary antibodies, including anti-UCHL1 (1:200 dilution) and anti-CDH1 (1:200 dilution). Briefly, the cells were fixed in $1 \mathrm{~mL} \mathrm{4 \%}$ paraformaldehyde, washed for $5 \mathrm{~min}$ in $1 \mathrm{~mL}$ PBS three times, permeabilized with $1 \mathrm{~mL} 0.5 \%$ Triton X-100 in PBS for $10 \mathrm{~min}$, and incubated with1 mL 10\% normal goat serum in DMEM/F12 for 30 $\mathrm{min}$ at room temperature to block non-specific binding. Cells were then incubated overnight at $4{ }^{\circ} \mathrm{C}$ with one of the primary antibodies mentioned above $(300 \mu \mathrm{L})$, given a further three 5 -min washes in $1 \mathrm{~mL}$ PBS, and exposed for $30 \mathrm{~min}$ at room temperature to $300 \mu \mathrm{L}$ Alexa Fluor 488-labeled donkey anti-rabbit IgG (1:500 dilution) mixed with $300 \mu \mathrm{L}$ DBA. After a final wash with $1 \mathrm{~mL}$ PBS, cells were stained with $300 \mu \mathrm{L} 10 \mu \mathrm{g} / \mathrm{mL}$ Hoechst 33342 to visualize nuclei, mounted with VECTASHIELD, and photographed under an fluorescence microscope (Eclipse 50i; Nikon, Tokyo, Japan). Germ cell clusters were also stained with antiOCT4 antibody (1:100 dilution; Abcam Inc., Cambridge, MA, USA), and the corresponding fluorescein isothiocyanate-conjugated goat anti-rabbit IgG (heavy and light chain) polyclonal secondary antibody (1:1000 dilution; Abcam, Hong Kong, China). For the negative control, primary antibodies were replaced by $3 \%$ BSA in PBS.

\section{Observation of SSC ultrastructure in testes and in vitro culture}

Testes were collected from a 1-month-old Bama mini-pig for ultrastructure analysis. Briefly, the testes were cut into small pieces and treated with a primary fixative solution of 50 $\mathrm{mL} 2.5 \%$ glutaraldehyde in PBS, $\mathrm{pH} 7.4$, at $4^{\circ} \mathrm{C}$ for $12 \mathrm{~h}$, before being fixed with $20 \mathrm{~mL} 2 \%$ osmic acid in PBS at $4^{\circ} \mathrm{C}$ for $1 \mathrm{~h}$, washed with $10 \mathrm{~mL}$ PBS, dehydrated, embedded in Epon 812 , and sectioned. The sections were stained for 20 min with $50 \mu \mathrm{L} 2 \%$ uranyl acetate in $70 \%$ alcohol, $\mathrm{pH} 4.2$, then $50 \mu \mathrm{L} 0.08 \mathrm{M}$ lead citrate solution, $\mathrm{pH} 12$, and subsequently analyzed by transmission electron microscopy, using which images were recorded.

SSC clusters were harvested by gentle pipetting, aggregated by centrifugation at 300 $g$, embedded as groups in $0.1 \%$ agarose, and treated with the same procedure as that used for testis tissue.

\section{Induced SSC differentiation}

SSCs from passages five and 15 were selected for differentiation. Cells were seeded on an STO feeder layer and incubated in DMEM/F12 containing 1X B27 supplement, $3 \mathrm{mg} /$ mL BSA (catalogue No. A7030; Sigma), 0.01 mM retinoic acid (catalogue No. R2625;Sigma), $2.5 \times 10^{-5} \mathrm{U} / \mathrm{mL}$ follicle-stimulating hormone (FSH; catalogue No. HOR-285; ProSpec, Rehovot, Israel), and $10 \mu \mathrm{g} / \mathrm{mL}$ insulin-like growth factor (IGF; catalogue No. I3769; Sigma) at $32^{\circ} \mathrm{C}$ in a $5 \% \mathrm{CO}_{2}$ atmosphere for 8 days. The cells were then harvested for flow cytometry analysis, with uninduced SSCs on an STO feeder layer being used as a negative control.

Genetics and Molecular Research 15 (3): gmr.15038602 


\section{RESULTS}

\section{Immunohistochemistry of testicular tissue}

Germ cells, including type A single and paired spermatogonia localized on the basement membrane of seminiferous tubules, were observed to express UCHL1, as were gonocytes adjacent to the seminiferous tubule lumina (Figure 1A). DBA staining was also detected in type A single and paired spermatogonia and gonocytes (Figure 1B). Nuclei were revealed using Hoechst 33342 staining (Figure 1C), while double staining revealed that germ cells expressing UCHL1 were also bound by DBA (Figure 1D).
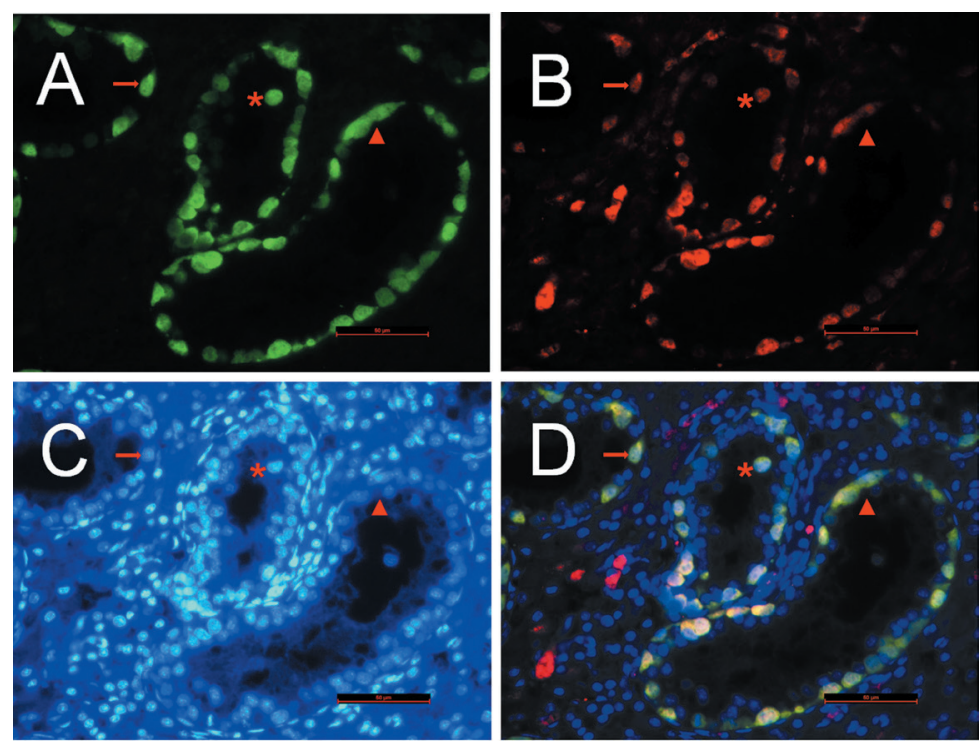

Figure 1. Immunofluorescent staining of testis sections. A. Expression of UCHL1 was observed in single type A spermatogonia (arrow), paired type A spermatogonia (arrowhead), and gonocytes (asterisk). B. Dolichos biflorus agglutinin binding was also evident in these same cells. C. Counterstaining was carried out with Hoechst33342 to visualize nuclei. D. Merged image. Scalebars $=50 \mathrm{~mm}$.

\section{Isolation and proliferation of SSCs}

The average number of harvested SSCs ranged from $0.5 \times 10^{5}$ to $2.5 \times 10^{5}$ after isolation. A combination of growth factors, including GDNF, GFral, and bFGF, has been shown to support the proliferation of these cells isolated from mice (Kubota et al., 2004); therefore, these same proteins were employed in the present study to promote the growth of Bama mini-pig SSCs. Small, round cells of various sizes were seen on the STO feeder layers after 3 days of culturing the isolated cells on 12-well plates (Figure 2A). The cells were passaged every 4-5 days. At passages one and two, no clustering among the few cells present was apparent, but by the third passage, cell clusters were evident (Figure 2B). Two days after passage, the cells aggregated and formed a flat cluster on the STO feeder layer. The clusters then grew in size and took on a three-dimensional form with unclear borders (Figure 2C). 
The germ cells continuously formed clusters throughout the subculturing process, as observed during passages 10 (Figure 2D), 15 (Figure 2E), and 20 (Figure 2F). To date, the cells have been cultured for over 100 days and maintain a normal growth rate.
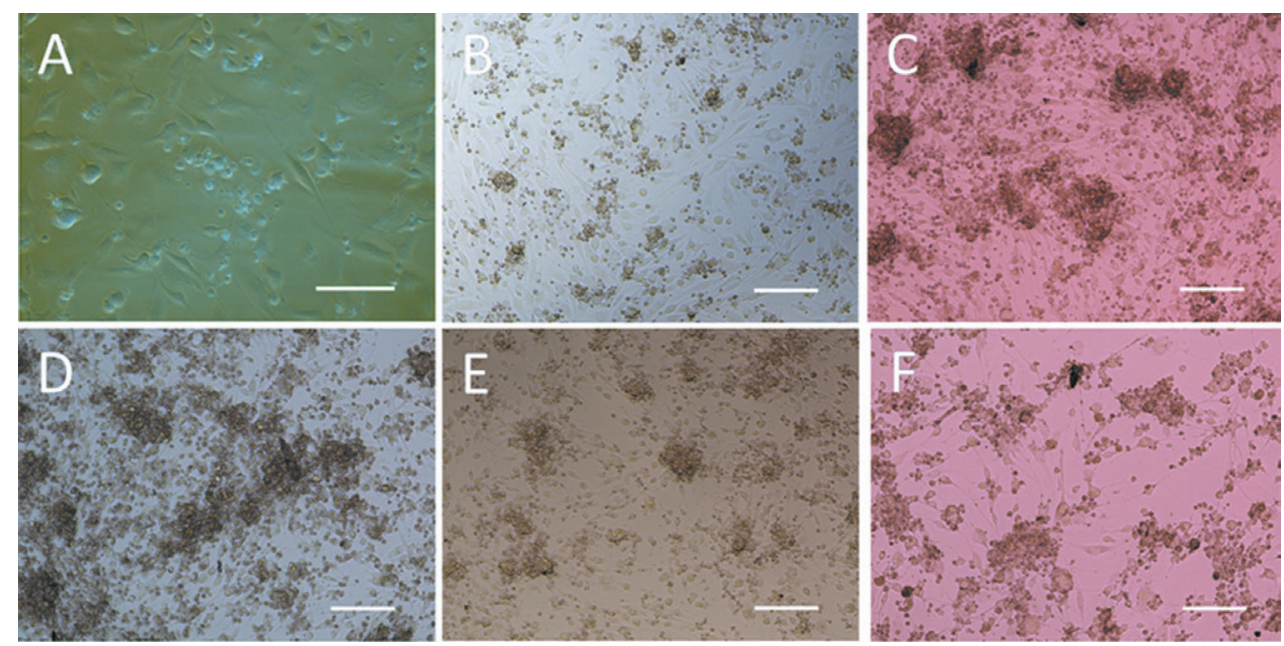

Figure 2. Proliferation of isolated cells in vitro. A. Passage zero; B. passage three; C. passage five; D. passage 10; E. passage 15; F. passage 20. Three-dimensional cell clusters appeared at passage three. Scale bars $=100 \mathrm{~mm}$.

\section{SSCs cultured in vitro expressed typical germ cell markers}

To characterize the clusters cultured in vitro, cells at passages five, 10 , and 15 were selected and stained with DBA and antibodies targeting germ cell markers, including UCHL1 and CDH1. At passage five, DBA bound to the clusters, double staining of which demonstrated that DBA-positive cells also expressed UCHL1 and CDH1. In addition, staining of clusters with an antibody binding OCT4 showed that a subset of cells expressed this stemcell specific marker. The same results were observed at passages 10 and 15 (Figure 3). Thus, immunocytochemical staining revealed the clusters to consist of SSCs.

\section{Comparison of cellular ultrastructure between in vitro and in vivo SSCs}

The environment to which SSCs are exposed in testes differs dramatically from that in a laboratory culture. In testis tissue, the many influences acting on SSCs result in a balance between proliferation and differentiation, but these factors are absent from in vitro cultures. It is not known whether such differences could lead to ultrastructure change. Thus, electron microscopy analysis was performed to compare SSCs in testes with those cultured in vitro. The former were round in shape, exhibited a large nucleus and a high nucleus-to-cytoplasm ratio (Figure 4A), and contained a small number of mitochondria in the cytoplasm (Figure 4B). The STO cells were large, contained a small nucleus, and showed a low nucleus-tocytoplasm ratio, making them distinct from SSCs (Figure 4C). SSCs cultured in vitro had a flat morphology and were tightly bound together (Figure 4D). 

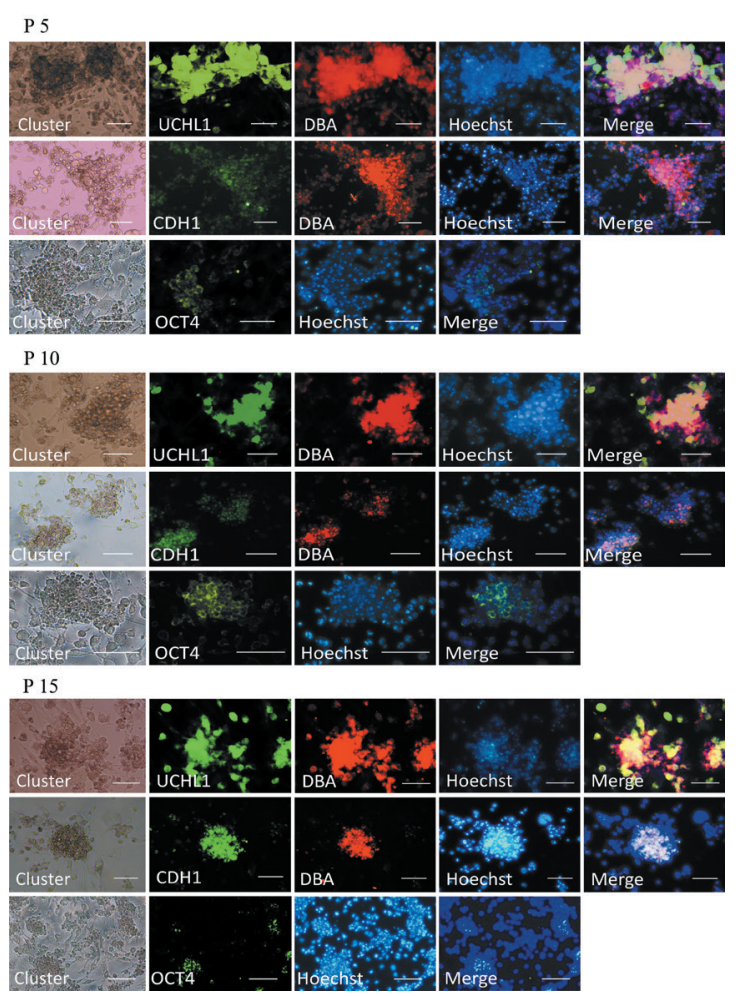

Figure 3. Immunocytochemical characterization of cultured cells at passages 5 (P 5), 10 (P 10), and 15 (P 15). Staining showed that the clusters expressed UCHL1 and CDH1, and could be bound by Dolichos biflorus agglutinin (DBA). A subset of cells in the clusters was found to be OCT4-positive. Hoechst 33342 was used to stain nuclei. Scale bars $=50 \mathrm{~mm}$.

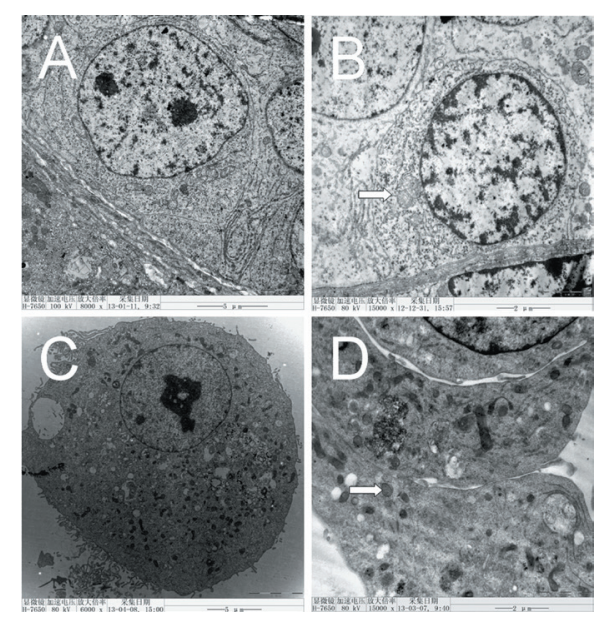

Figure 4. Ultrastructure observation of SSCs in testis tissue and those cultured in vitro. A. and B. SSC in testis tissue. Mitochondria (arrow) were observed in the cytoplasm. C. STO cell ultrastructure. D. Image from an SSC cluster cultured in vitro. Mitochondria (arrow) were observed in the cytoplasm. 


\section{SSCs cultured in vitro can undergo meiosis}

Proliferation of SSCs in the laboratory is carried out to provide enough cells for research into their differentiation, and requires that cultured SSCs maintain their stem cell properties. To investigate whether these cells are able to undergo meiosis when cultured in vitro, their DNA content was determined by flow cytometry analysis after 8 days of induction. No haploid peak was observed in the control group (Figure 5A), but one was evident after induction at passages five (Figure 5B) and 10 (Figure 5C), showing that SSCs cultured in vitro can be induced to undergo meiosis.
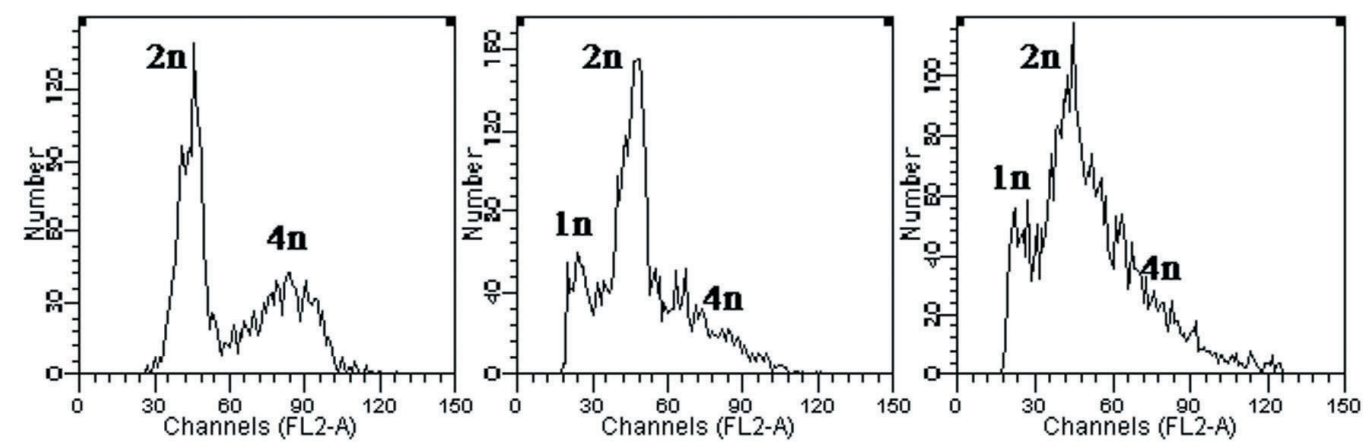

Figure 5. DNA content of cells analyzed by flow cytometry. A. Uninduced spermatogonial stem cells (SSCs) on an STO feeder layer. B. SSCs at passage five following induction. C. SSCs at passage 10 following induction.

\section{DISCUSSION}

The development of germ cells in testes is a complex and organized process. Primordial germ cells (PGCs), which form at an early stage of fetal development, are the origin of the germline. In males, PGCs are enclosed by the spermatic cords and give rise to gonocytes. These cells migrate to the basement membrane of the seminiferous tubules after birth and generate type A spermatogonia (Kluin and de Rooij, 1981), which maintain spermatogenesis throughout post-pubescent life. Generally, SSCs in newborn piglet testes are undifferentiated and their low numbers preclude the isolation of sufficient cells for culture. However, it has been reported that SSCs can be isolated from piglets (Zheng et al., 2013). For instance, Goel et al. (2007) described the purification of SSCs from piglets aged 3 weeks, and these cells have also been isolated from 7-month-old calves (Izadyar et al., 2002). Moreover, SSCs can be successfully obtained from adult animals (Mohamadi et al., 2012). In this work, the testes of a 1-month-old Bama mini-pig were used to isolate SSCs.

The lectin DBA, which had previously been found to bind to porcine PGCs, has been identified as a specific marker of porcine gonocytes and primitive spermatogonia, but does not bind to SSCs in pig testis tissue by the age of 5 months (Goel et al., 2007). Thus, DBA binding cannot be regarded as a universal SSC indicator. In this study, immunohistochemical staining showed that DBA could bind to these cells in the testis tissue of a young piglet, and all cultured SSCs were isolated from the same testis. Therefore, DBA was used to identify these cells in the present work. It has been reported that all type A spermatogonia demonstrate stem 
cell potential (Phillips et al., 2010). In this research, DBA was seen to bind some interstitial testis cells, but never Sertoli cells. UCHL1 staining was found in gonocytes and type A single and paired spermatogonia, consistent with previous findings (Luo et al., 2006). Unlike DBA binding, UCHL1 expression is observed in undifferentiated porcine SSCs at all ages, and has been used to identify these cells in pigs, buffalo, cows, and humans (Luo et al., 2006; Goel et al., 2010; He et al., 2010; Fujihara et al., 2011). In the present study, expression of this protein by SSCs in testis tissue was also observed; therefore, it can be used to distinguish Bama minipig SSCs cultured in vitro. Cells staining positive for UCHL1 were of various diameters, similar to the results reported in a previous study using boar tissue (Luo et al., 2006). Thus, the SSC population comprises cells of several sizes.

There are a number of approaches for isolating SSCs, including discontinuous density gradient centrifugation, separation with immunomagnetic beads, and differential plating, each of which has its disadvantages. For instance, in discontinuous density gradient centrifugation, somatic cells may be mixed with SSCs, and a yield of $69 \%$ germ cells has been reported using this method (Goel et al., 2007). Separation using immunomagnetic beads can exclude SSCs that fail to bind to the antibody used. This technique has been employed to isolate THY1-positive SSCs from a male dairy goat (Wu et al., 2013). Differential plating, meanwhile, may result in the loss of some SSCs through their attachment to the bottom of the collagen-coated plate after an extended culture period. In a previous study, $73 \%$ of the cells isolated using this procedure were found to be SSCs (Izadyar et al., 2002). Here, a modification of the differential plating process was employed to isolate Bama mini-pig SSCs, in that gentle pipetting was carried out 20 min after seeding to minimize attachment of these cells to the collagen-coated plate.

A defined medium is essential for SSC culture in order to eliminate unknown factors that may affect cellular physiology. Both serum and feeder layers contain many such uncharacterized components. Mouse SSCs have been shown to proliferate in serum, serumfree, feeder-free, and feeder- and serum-free culture systems (Kanatsu-Shinohara et al., 2003; Kanatsu-Shinohara et al., 2005; Araki et al., 2010; Kanatsu-Shinohara et al., 2011). Goel et al. (2007) maintained isolated porcine gonocytes for 7 days in DMEM/F12 containing 10\% serum, while more recently, Zheng et al. (2013) incubated piglet SSCs with different serum concentrations and growth factors, with a primary culture time of 10 days. Previous research has shown that it is possible to maintain porcine SSCs for 60 days at $31^{\circ} \mathrm{C}$ (Lee et al., 2013). In the present work, Bama mini-pig SSCs were cultured in serum-free medium for at least 100 days and passaged over 20 times, while immunocytochemistry revealed cell clusters to be positive for DBA, UCHL1, and CDH1, confirming them to be comprised of SSCs. Thus, a sufficient number of SSCs were produced to be used for transgenic manipulation and exploration of the mechanism underlying spermatogenesis.

SSCs cultured in vitro are free from the influence of factors present in testes, meaning that the culture medium environment is completely different from that in vivo. We speculated whether this change could lead to a difference in ultrastructure, especially the number of mitochondria. The ultrastructure of SSCs from fish has been described in previous study, in which these cells were described as containing a small number of mitochondria (Lacerda et al., 2014). In our work, we found that SSCs cultured in vitro were of a similar character to those in testis tissue. Aside from the flat shape of the former, owing to the formation of clusters that deformed the cells of which they were comprised, no other difference was found.

It has been reported that ESCs can undergo meiosis in medium supplemented with retinoic acid (Geijsen et al., 2004). Furthermore, stem cell factor triggers the differentiation of 
type A spermatogonia (Feng et al., 2002), while meiosis in SSCs is induced by the presence of testosterone and FSH (Minaee Zanganeh et al., 2013). In the present study, retinoic acid, IGF, and FSH were used in the differentiation medium. To investigate whether the SSCs cultured in vitro underwent meiosis after induction, they were harvested for DNA content analysis. A haploid peak was observed following induction, indicating the presence of haploid cells among the SSCs. Hence, our data show that meiosis was successfully induced in these cells, demonstrating that SSCs cultured using our system maintain their stem cell potential and could be useful in further research.

\section{CONCLUSIONS}

To date, we have maintained an in vitro Bama mini-pig SSC culture for over 100 days. These SSCs retain their normal proliferation ability and continue to form clusters. Moreover, they are able to undergo meiosis after induction, providing a culture system generating a sufficient number of cells in vitro to function as a platform for further research.

\section{Conflicts of interest}

The authors declare no conflict of interest.

\section{ACKNOWLEDGMENTS}

Research supported by the Natural Science Foundation of China (\#31260277), the Guangxi University Foundation (\#20100244), and the Guangxi High Education Innovation Research Group and Eminent Scholar Project.

\section{REFERENCES}

Aoshima K, Baba A, Makino Y and Okada Y (2013). Establishment of alternative culture method for spermatogonial stem cells using knockout serum replacement. PLoS One 8: e77715. http://dx.doi.org/10.1371/journal.pone.0077715

Araki Y, Sato T, Katagiri K, Kubota Y, et al. (2010). Proliferation of mouse spermatogonial stem cells in microdrop culture. Biol. Reprod. 83: 951-957. http://dx.doi.org/10.1095/biolreprod.109.082800

Buaas FW, Kirsh AL, Sharma M, McLean DJ, et al. (2004). Plzf is required in adult male germ cells for stem cell selfrenewal. Nat. Genet. 36: 647-652. http://dx.doi.org/10.1038/ng1366

Feng LX, Chen Y, Dettin L, Pera RA, et al. (2002). Generation and in vitro differentiation of a spermatogonial cell line. Science 297: 392-395. http://dx.doi.org/10.1126/science.1073162

Fujihara M, Kim SM, Minami N, Yamada M, et al. (2011). Characterization and in vitro culture of male germ cells from developing bovine testis. J. Reprod. Dev. 57: 355-364. http://dx.doi.org/10.1262/jrd.10-185M

Geijsen N, Horoschak M, Kim K, Gribnau J, et al. (2004). Derivation of embryonic germ cells and male gametes from embryonic stem cells. Nature 427: 148-154. http://dx.doi.org/10.1038/nature02247

Goel S, Sugimoto M, Minami N, Yamada M, et al. (2007). Identification, isolation, and in vitro culture of porcine gonocytes. Biol. Reprod. 77: 127-137. http://dx.doi.org/10.1095/biolreprod.106.056879

Goel S, Reddy N, Mandal S, Fujihara M, et al. (2010). Spermatogonia-specific proteins expressed in prepubertal buffalo (Bubalus bubalis) testis and their utilization for isolation and in vitro cultivation of spermatogonia. Theriogenology 74: 1221-1232. http://dx.doi.org/10.1016/j.theriogenology.2010.05.025

Guan K, Nayernia K, Maier LS, Wagner S, et al. (2006). Pluripotency of spermatogonial stem cells from adult mouse testis. Nature 440: 1199-1203. http://dx.doi.org/10.1038/nature04697

He Z, Kokkinaki M, Jiang J, Dobrinski I, et al. (2010). Isolation, characterization, and culture of human spermatogonia. Biol. Reprod. 82: 363-372. http://dx.doi.org/10.1095/biolreprod.109.078550

Genetics and Molecular Research 15 (3): gmr.15038602 
Hu LL, Lu YQ, Xu HY, Yang XG, et al. (2015). Production of hGFAP-DsRed transgenic Guangxi Bama mini-pigs via somatic cell nuclear transfer. Genet. Mol. Res. 14: 16285-16296. http://dx.doi.org/10.4238/2015.December.8.19

Izadyar F, Spierenberg GT, Creemers LB, den Ouden K, et al. (2002). Isolation and purification of type A spermatogonia from the bovine testis. Reproduction 124: 85-94. http://dx.doi.org/10.1530/rep.0.1240085

Kala S, Kaushik R, Singh KP, Kadam PH, et al. (2012). In vitro culture and morphological characterization of prepubertal buffalo (Bubalus bubalis) putative spermatogonial stem cell. J. Assist. Reprod. Genet. 29: 1335-1342. http://dx.doi. org/10.1007/s10815-012-9883-y

Kanatsu-Shinohara M, Ogonuki N, Inoue K, Miki H, et al. (2003). Long-term proliferation in culture and germline transmission of mouse male germline stem cells. Biol. Reprod. 69: 612-616. http://dx.doi.org/10.1095/ biolreprod.103.017012

Kanatsu-Shinohara M, Miki H, Inoue K, Ogonuki N, et al. (2005). Long-term culture of mouse male germline stem cells under serum-or feeder-free conditions. Biol. Reprod. 72: 985-991. http://dx.doi.org/10.1095/biolreprod.104.036400

Kanatsu-Shinohara M, Inoue K, Ogonuki N, Morimoto H, et al. (2011). Serum- and feeder-free culture of mouse germline stem cells. Biol. Reprod. 84: 97-105. http://dx.doi.org/10.1095/biolreprod.110.086462

Kanatsu-Shinohara M, Ogonuki N, Matoba S, Morimoto H, et al. (2014). Improved serum- and feeder-free culture of mouse germline stem cells. Biol. Reprod. 91: 88. http://dx.doi.org/10.1095/biolreprod.114.122317

Kluin PM and de Rooij DG (1981). A comparison between the morphology and cell kinetics of gonocytes and adult type undifferentiated spermatogonia in the mouse. Int. J. Androl. 4: 475-493. http://dx.doi.org/10.1111/j.1365-2605.1981. tb00732.x

Kubota H, Avarbock MR and Brinster RL (2004). Growth factors essential for self-renewal and expansion of mouse spermatogonial stem cells. Proc. Natl. Acad. Sci. USA 101: 16489-16494. http://dx.doi.org/10.1073/pnas.0407063101

Lacerda SM, Costa GM and de França LR (2014). Biology and identity of fish spermatogonial stem cell. Gen. Comp. Endocrinol. 207: 56-65. http://dx.doi.org/10.1016/j.ygcen.2014.06.018

Lee WY, Park HJ, Lee R, Lee KH, et al. (2013). Establishment and in vitro culture of porcine spermatogonial germ cells in low temperature culture conditions. Stem Cell Res. (Amst.) 11: 1234-1249. http://dx.doi.org/10.1016/j. scr.2013.08.008

Li B, Zhuang M, Wu C, Niu B, et al. (2016). Bovine male germline stem-like cells cultured in serum- and feeder-free medium. Cytotechnology [Epub ahead of print].

Lim JJ, Kim HJ, Kim KS, Hong JY, et al. (2013). In vitro culture-induced pluripotency of human spermatogonial stem cells. BioMed Res. Int. 2013: 143028. http://dx.doi.org/10.1155/2013/143028

Luo J, Megee S, Rathi R and Dobrinski I (2006). Protein gene product 9.5 is a spermatogonia-specific marker in the pig testis: application to enrichment and culture of porcine spermatogonia. Mol. Reprod. Dev. 73: 1531-1540. http:// dx.doi.org/10.1002/mrd.20529

Meng X, Lindahl M, Hyvönen ME, Parvinen M, et al. (2000). Regulation of cell fate decision of undifferentiated spermatogonia by GDNF. Science 287: 1489-1493. http://dx.doi.org/10.1126/science.287.5457.1489

Minaee Zanganeh B, Rastegar T, Habibi Roudkenar M, Ragerdi Kashani I, et al. (2013). Co-culture of spermatogonial stem cells with sertoli cells in the presence of testosterone and FSH improved differentiation via up-regulation of post meiotic genes. Acta Med. Iran. 51: 1-11.

Mohamadi SM, Movahedin M, Koruji SM, Jafarabadi MA, et al. (2012). Comparison of colony formation in adult mouse spermatogonial stem cells developed in Sertoli and STO coculture systems. Andrologia 44 (Suppl 1): 431-437. http:// dx.doi.org/10.1111/j.1439-0272.2011.01201.x

Oatley MJ, Kaucher AV, Racicot KE and Oatley JM (2011). Inhibitor of DNA binding 4 is expressed selectively by single spermatogonia in the male germline and regulates the self-renewal of spermatogonial stem cells in mice. Biol. Reprod. 85: 347-356. http://dx.doi.org/10.1095/biolreprod.111.091330

Pesce M, Wang X, Wolgemuth DJ and Schöler H (1998). Differential expression of the Oct-4 transcription factor during mouse germ cell differentiation. Mech. Dev. 71: 89-98. http://dx.doi.org/10.1016/S0925-4773(98)00002-1

Phillips BT, Gassei K and Orwig KE (2010). Spermatogonial stem cell regulation and spermatogenesis. Philos. Trans. $R$. Soc. Lond. B Biol. Sci. 365: 1663-1678. http://dx.doi.org/10.1098/rstb.2010.0026

Takehashi M, Kanatsu-Shinohara M and Shinohara T (2010). Generation of genetically modified animals using spermatogonial stem cells. Dev. Growth Differ. 52: 303-310. http://dx.doi.org/10.1111/j.1440-169X.2009.01167.x

Tanaka SS, Toyooka Y, Akasu R, Katoh-Fukui Y, et al. (2000). The mouse homolog of Drosophila Vasa is required for the development of male germ cells. Genes Dev. 14: 841-853.

Tokuda M, Kadokawa Y, Kurahashi H and Marunouchi T (2007). CDH1 is a specific marker for undifferentiated spermatogonia in mouse testes. Biol. Reprod. 76: 130-141. http://dx.doi.org/10.1095/biolreprod.106.053181

von Schönfeldt V, Wistuba J and Schlatt S (2004). Notch-1, c-kit and GFRalpha-1 are developmentally regulated markers

Genetics and Molecular Research 15 (3): gmr.15038602 
for premeiotic germ cells. Cytogenet. Genome Res. 105: 235-239. http://dx.doi.org/10.1159/000078194

Wu J, Song W, Zhu H, Niu Z, et al. (2013). Enrichment and characterization of Thy1-positive male germline stem cells (mGSCs) from dairy goat (Capra hircus) testis using magnetic microbeads. Theriogenology 80: 1052-1060. http:// dx.doi.org/10.1016/j.theriogenology.2013.08.003

Zheng Y, Tian X, Zhang Y, Qin J, et al. (2013). In vitro propagation of male germline stem cells from piglets. J. Assist. Reprod. Genet. 30: 945-952. http://dx.doi.org/10.1007/s10815-013-0031-0

Zheng Y, Thomas A, Schmidt CM and Dann CT (2014). Quantitative detection of human spermatogonia for optimization of spermatogonial stem cell culture. Hum. Reprod. 29: 2497-2511. http://dx.doi.org/10.1093/humrep/deu232

Zhou Q, Wang M, Yuan Y, Wang X, et al. (2016). Complete meiosis from embryonic stem cell-derived germ cells in vitro. Cell Stem Cell 18: 330-340. http://dx.doi.org/10.1016/j.stem.2016.01.017 